\title{
Leprosy in peripheral nerves: histopathological findings in 119 untreated patients in Nepal
}

\author{
J C PEDLEY, D J HARMAN, H WAUDBY, AND A C MCDOUGALL \\ From the United Mission Hospital, Tansen, Palpa, Nepal, the Leprosy Study Centre, London, \\ and the Slade Hospital, Oxford
}

S U M MARY From a series of 342 nerve biopsies taken by one clinician over a period of 12 years in Nepal, this paper describes the histopathological findings in 153 biopsies from 119 patients suffering from tuberculoid, borderline (dimorphous) or lepromatous leprosy, who were untreated at the time of first presentation and diagnosis. They were taken during the course of other studies, mainly concerned with the mode of transmission of leprosy, and which included biopsies of skin, dartos muscle, nasal mucous membrane and nipple, results of which have already been published. Examination of serial sections by light microscopy revealed a density of cellular infiltration in non-lepromatous cases, or of bacilli in macrophages and Schwann cells in lepromatous cases, which was marked in degree and usually widespread from one end of the biopsy to the other. Intraneural caseation was recorded in four patients with tuberculoid or borderline-tuberculoid leprosy, and many others in this part of the spectrum showed extensive disruption of perineurial and endoneurial structure. In lepromatous patients, the numbers of bacilli in the endoneurial area not infrequently exceeded one thousand per oil immersion field. Although well known to histopathologists familiar with this disease, it is considered that the significance of these findings, in patients presenting for the first time, is not well appreciated by those working in general medicine, neurology, epidemiology, or even in leprosy control.

There are very few organisms which enter peripheral or dermal nerves, and amongst mycobacteria, the leprosy bacillus is unique in this respect. Since the early days of clinical observation in leprosy, it has been obvious that nerves are heavily involved and some authors have stated that neural tissues, and particularly Schwann cells, are the most heavily and consistently affected; others consider that bacilli first enter nerves in the genesis of all leprous lesions, and that they persist in them long after disappearance from other tissues as a result of treatment. Various aspects of neuropathy in leprosy have already been well described; publications from recent years have dealt with the clinical findings. ${ }^{1-7}$ The histopathological features have been particularly well reviewed by Weddell and Pearson ${ }^{22}$ and the present paper does not attempt to add new knowledge to this aspect of leprosy neuropathy or to shed new

Address for reprint requests - Dr AC McDougall, The Sade Hospital, Headington, Oxford OX3 $7 \mathrm{JH}$.

Accepted 14 October 1979 light on its pathogenesis. It does, however, set out to illustrate a fact which is not always well understood even by those working in leprosynamely that in this disease on first presentation for diagnosis, the patient's peripheral nerves may already be heavily infiltrated with defensive cells, or infected by large numbers of bacilli. We report the extent and severity of this involvement in nerve biopsies from 119 patients with various forms of leprosy in Nepal, who were completely untreated on first presentation.

\section{Patients and Methods}

The patients were under the care of one of us (JCP) at the United Mission Hospital, Tansen, Palpa, Nepal, during the 12 years 1962 to 1974. They were mainly out-patients, and almost entirely self-reporting, apart from a small number, perhaps 10 per cent of the total, who were found to have leprosy as a result of examination of household or family contacts. They came on foot over the mountains, covering 15 to 20 miles a day, from distances up to 200 
miles from the hospital. From the total of 342 biopsies in the 12-year period, including both treated and untreated patients, there were 302 men and 40 women, a difference which may be partly accounted for by the simple fact that women work so hard in Nepal that they do not have time to attend. Some patients were admitted for a few days or weeks, but for the most part they were examined and assessed as out-patients. Treatment was in the form of oral dapsone (DDS) in a dose of 50 to $100 \mathrm{mg}$ daily and usually enough was given for three months, though in the case of those living at great distance, a year's supply was given at a time. In 1962, the default rate, defined as nonattendance for a year or more, was in the region of 30 per cent, and by the end of the study (1974) it was 25 per cent.

Selection of patients: The total of leprosy patients registered and under supervision at the hospital during the period of study was approximately 5500, from whom biopsies of peripheral nerve were taken as part of a larger series of studies, mainly concerned with mode of transmission of leprosy. ${ }^{23-27}$ Of the total of 342 biopsies, 173 were from treated leprosy patients, and 16 were taken for other diagnostic purposes, but from patients with no clinical or other evidence of leprosy; these are not described in the present paper. The remaining 153 biopsies came from 119 patients who were completely untreated on first presentation, and their classification, based on history, clinical findings, lepromin test, slit-skin smears, skin biopsy, and on the nerve biopsy itself is shown in the table, the system of classification, including interpretation of the lepromin test, being that of Ridley and Jopling. ${ }^{28}$ The term lepromatous is used here to include both polar (LLp) and sub-polar (LLs) patients (the latter being a subgroup of lepromatous leprosy, identified histologically and clinically by Ridley and Waters in $1969,{ }^{29}$ tending to 'reverse' (upgrade) to a borderline-lepromatous (BL) classification on treatment). The lepromin was of Mitsuda type, standardised to WHO specification to contain $1.6 \times 10^{8}$ acid-fast bacilli per $\mathrm{ml}$.

Nerve biopsy technique: The selection of nerves for biopsy depended largely on the clinical findings; several patients had more than one biopsy of skin or nerve or both in order to collect data on the classification and state of activity of lesions in different parts of the body on first presentation. Sensory nerves only were chosen and they were usually either visible or palpable clinically (or both), the most commonly used being the greater auricular on the side of the neck, the terminal radial or the terminal ulnar at the wrist, less commonly the superficial peroneal or the sural nerve in the leg. The details of biopsy technique have recently been described in full ${ }^{30}$ and it is here only necessary to add that a high success rate was ensured by 1: adequate exposure of the nerve under good light, 2: the use of a nerve hook to bring the nerve gently out of the wound, 3: the removal of an adequate length of nerve tissue, the incision going down far enough to include at least part of a bundle, and 4: inspection of the cut end of every nerve biopsy with a hand lens to ensure that it did contain nerve fibres. From the total of 153 biopsies, only five $(3 \cdot 3$ per cent $)$ failed to reveal nerve tissue, one consisting of blood vessel wall. No patient registered complaints directly related to the procedure, and on followup, in many cases for five years or more, there was no evidence that the procedure itself had led to neuritis or deterioration in sensory function in the area concerned.

Fixation, processing and staining: Biopsies were fixed in a modified formol-Zenker solution for 15 to 24 hours, then transferred to $70 \%$ alcohol, embedded in paraffin wax and cut, in longitudinal and transverse planes at $5 \mu \mathrm{m}$. Staining was with a combined Fite-Faraco modification of ZiehlNeelsen and a trichrome ('TRIFF'). ${ }^{31}$

\section{Results}

These are summarised in table 1. Apart from the five biopsy 'failures' noted above, and six other tissues which showed nonspecific changes (and were not diagnostic of any form of leprosy), nine biopsies were completely normal.

Table 1 Classification (Ridley and Joplin, 1966) of the type of leprosy in 153 nerve biopsies from untreated patients

\begin{tabular}{lc}
\hline Type of leprosy & Number of biopsies \\
\hline Tuberculoid (TT) & 13 \\
Borderline-Tuberculoid (BT) & 20 \\
Borderline (BB) & 18 \\
Borderline-Lepromatous (BL) & $60^{*}$ \\
Lepromatous (LL) & $22^{*}$ \\
Patients with leprosy (clinically and bacteriologically & \\
proven) in whom the biopsy: & 9 \\
(1) revealed normal nerve tissue & \\
(2) failed to reveal nerve tissue (blood vessel or & 5 \\
(3) Rennective tissue, taken by mistake) & 6 \\
\hline
\end{tabular}

*These comparatively high figures for BL and LL leprosy do not necessarily reflect the situation for the country or even the area served by this hospital. The lepromatous rate for Nepal generally 36 is $20 \%$. 
These 20 were in fact all from patients in whom the clinical signs and skin histopathology were nevertheless diagnostic of borderline (dimorphous) leprosy, and the normal or nonspecific findings were considered compatible with the patchy and often asymmetrical distribution of lesions which typically occurs in forms of leprosy intermediate between the tuberculoid and lepromatous poles. In all patients with abnormal findings in the nerve biopsy, the skin biopsy was also abnormal and in every instance the type (classification) of leprosy was in agreement. The lepromin test was uniformly negative in all lepromatous (LLp and LLs) and borderlinelepromatous (BL) cases; results in non-lepromatous cases accorded with those already described in detail for patients in other parts of the spectrum. $^{28}$

\section{Lepromatous ( $L L p$ and $L L s$ ) biopsies}

All 22 showed large numbers of bacilli, some of them in globus arrangement, scattered throughout the epineurial, perineurial and endoneurial areas (figs 1 and 2). Most were in macrophages or Schwann cells, but perineurial cells and fibroblasts were also involved. In many cases bacilli, often as globi, were seen in the cytoplasm of endothelial lining cells of neural vessels (fig 3). The morphology of a high percentage of freestanding bacilli as seen in sections was solidstaining throughout their entire length, a finding which has been equated with viability. ${ }^{32}$ In several biopsies, the numbers of bacilli exceeded 1000 per oil immersion field, and they were not infrequently so dense and numerous as to be uncountable.

\section{Borderline-lepromatous (BL) biopsies}

All 60 showed considerable numbers of bacilli and infiltrating cells, together with disturbance of normal perineurial and endoneurial structure, and here again the changes were widespread throughout the tissue biopsy. There were, not infrequently, areas of inflammatory oedema

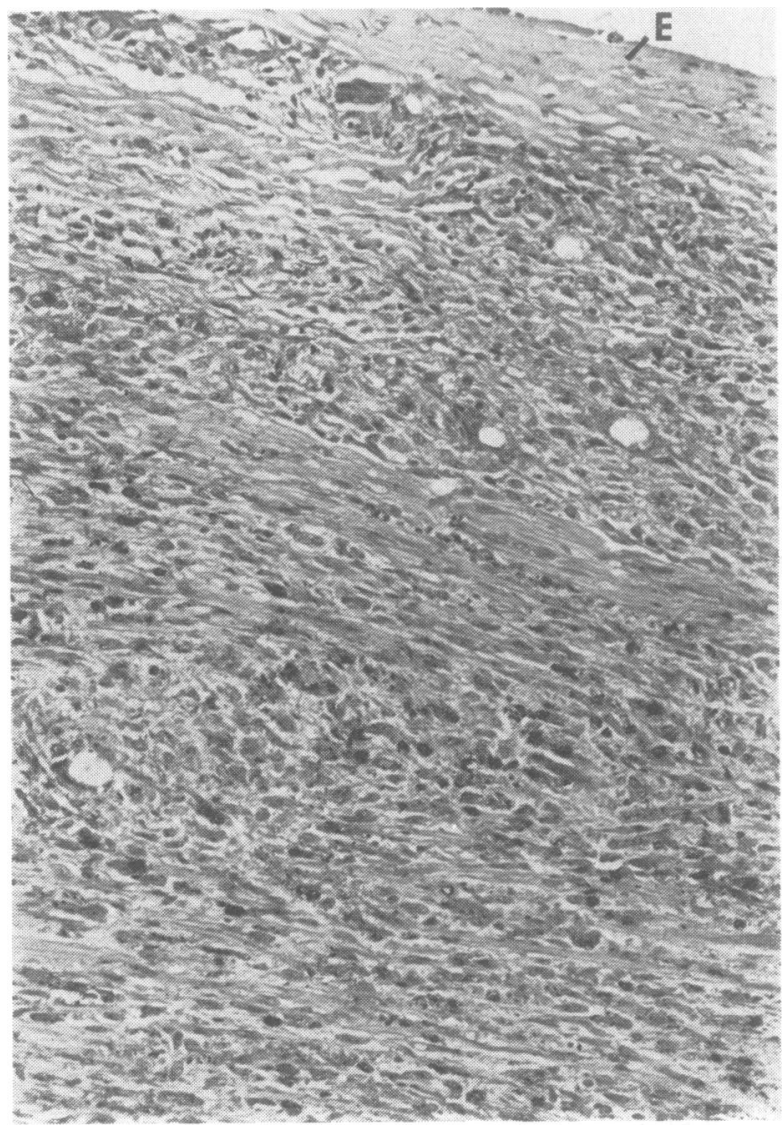

Fig 1 Dorsal cutaneous branch of right ulnar nerve at wrist. LL leprosy. Longitudinal section. $E=$ epineurium. Perineurium is hard to distinguish and the bulk of tissue shown consists of endoneurium, in which macrophages and Schwann cells contain large numbers of Mycobacterium leprae. TRIFF stain. Original magnification $\times 250$. 


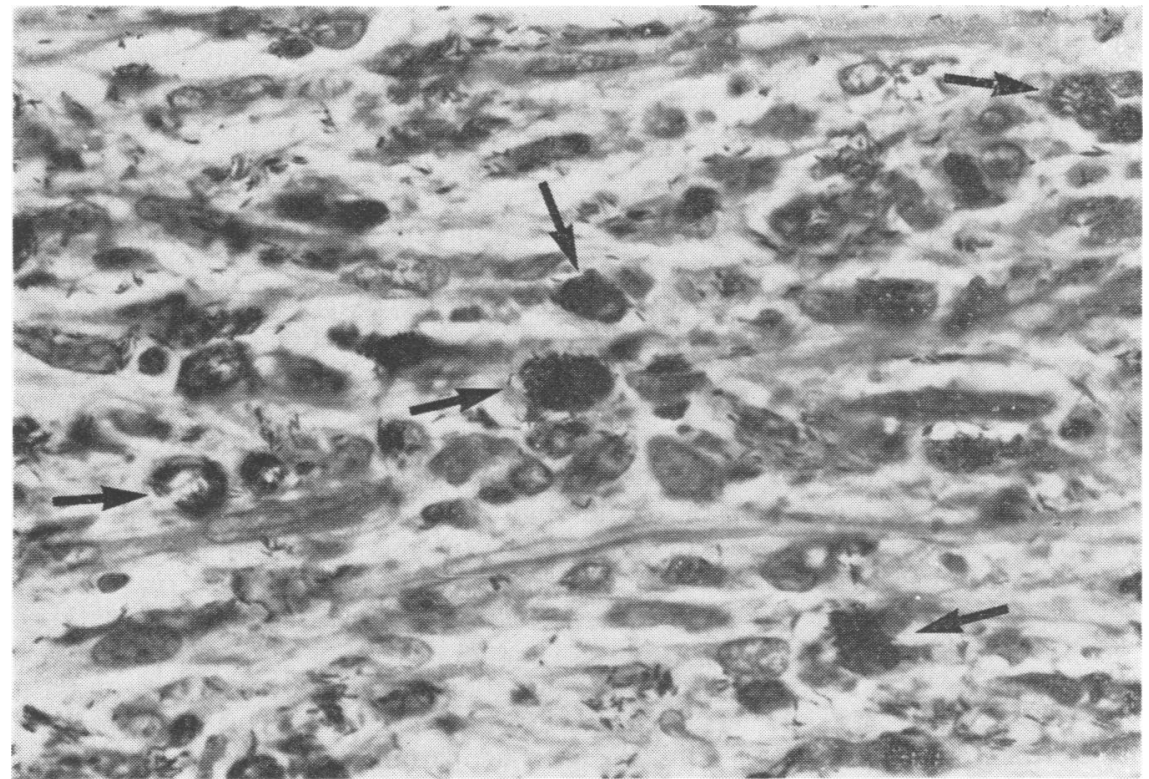

Fig 2 Same biopsy

as fig 1. The

endoneurial zone

contains large

numbers of bacilli,

many of them solid-

staining, in

macrophages and

Schwann cells. There

are numerous globi

(arrowed) containing

uncountable numbers

of bacilli. TRIFF

stain. Original

magnification $\times 1000$.

associated with infiltrating cells in the endoneurial area. Despite the lower concentrations of bacilli in this group, compared with the LL group described above, the disturbance of neural structure revealed by histopathological examination was invariably greater, and the significance of this, in relation to the often widespread involvement of nerves recorded clinically, will be discussed below.
Borderline (BB) biopsies (18 cases)

Bacilli were present in moderate numbers, with a predominant epithelioid cell infiltrate, together with a small element of lymphocytes; abnormal lamination of the perineurium was present in several cases as already described. ${ }^{33}$ Once again, most of these 18 biopsies showed changes which occupied the entire extent of the tissues presented for examination.

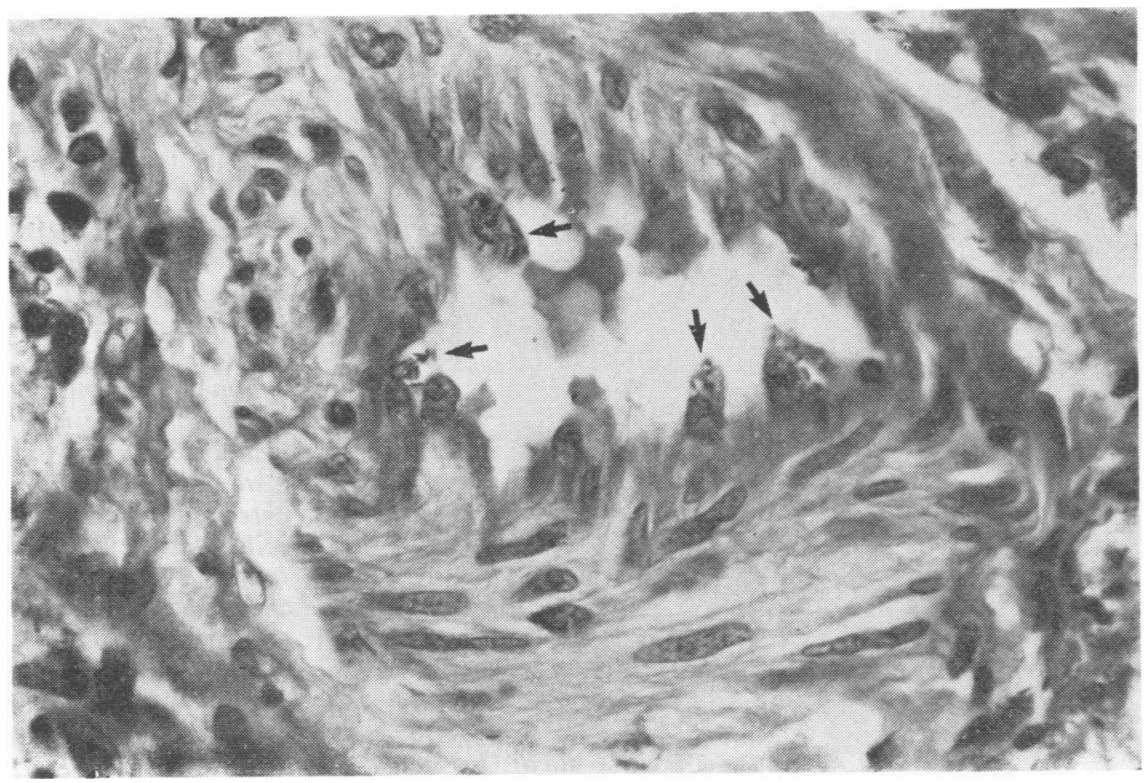

Fig 3 Same biopsy as figs $I$ and 2. $A$ medium sized arteriole in the epineurium contains many bacilli in endothelial lining cells (arrowed). TRIFF stain. Original magnification $\times 1000$. 


\section{Borderline-tuberculoid (BT) and Tuberculoid}

(TT) biopsies (33 cases)

These showed a densely packed infiltrate of granulomatous cells from one end to the other. In many instances, subdivision into epineurial, perineurial and endoneurial areas was obliterated, and Schwann cells, myelin and axons could not be clearly identified over large areas. Bacilli were typically few in number in BT, and even fewer in TT patients, though they were in fact identified in all biopsies except four out of the 33 in this combined group. Abscess formation was found in the endoneurial area in four patients, two with BT and two with TT leprosy; in one instance (fig $4 a$ and b, fig 5), the necrotic area occupied approximately $50 \%$ of the specimen and had obviously destroyed all neural elements over an area several $\mathrm{mm}$ in diameter.

\section{Discussion}

It bears repetition that these findings were recorded in the peripheral nerves of patients on first presentation for diagnosis and treatment. In the lepromatous (LL) forms, the sheer bulk of bacilli may be disruptive or even space-occupying (fig 2), but their presence, at this anergic end of the spectrum, does not give rise to cellmediated immune responses which are in themselves damaging, as occurs in the tuberculoid and borderline forms of this infection. However, either before or after treatment, bacilli in lepro- matous leprosy may become antigenic and provoke an immune-complex reaction, commonly called erythema nodosum leprosum (ENL) because of its frequent involvement of the skin, although numerous other tissues may be affected, including nerves. ${ }^{42} \mathrm{~A}$ further point of concern about the invasion of nerves by Mycobacterium leprae, is that it may be able to survive within Schwann cells for relatively long periods, ${ }^{22}$ and also despite the administration of adequate drug therapy over a period of many years. ${ }^{34}$ In borderline-tuberculoid (BT) and tuberculoid (TT) leprosy on the other hand, the influx of infiltrating cells in response to relatively small numbers of bacilli may create a battlefield in vitally important tissue. In this area of the spectrum, cell-mediated immune responses are in fact the main mechanisms involved in tissue destruction. ${ }^{35}$ A point of some interest which arises from the present study concerns the classification of those patients, who, on consideration of the combined clinical and histopathological findings (and clinical photographs, when available) were worst affected neurologically. Tissue necrosis, such as that illustrated in figs 4 and 5 , occurred in tuberculoid (TT) or borderline-tuberculoid (BT) patients, and was clearly disastrous in the area of nerve concerned, but it was localised. Considering the factors of numbers of bacilli, numbers of infiltrating cells, physical disruption of endoneurial and perineurial structure, together with the clinical and photographic evidence, the

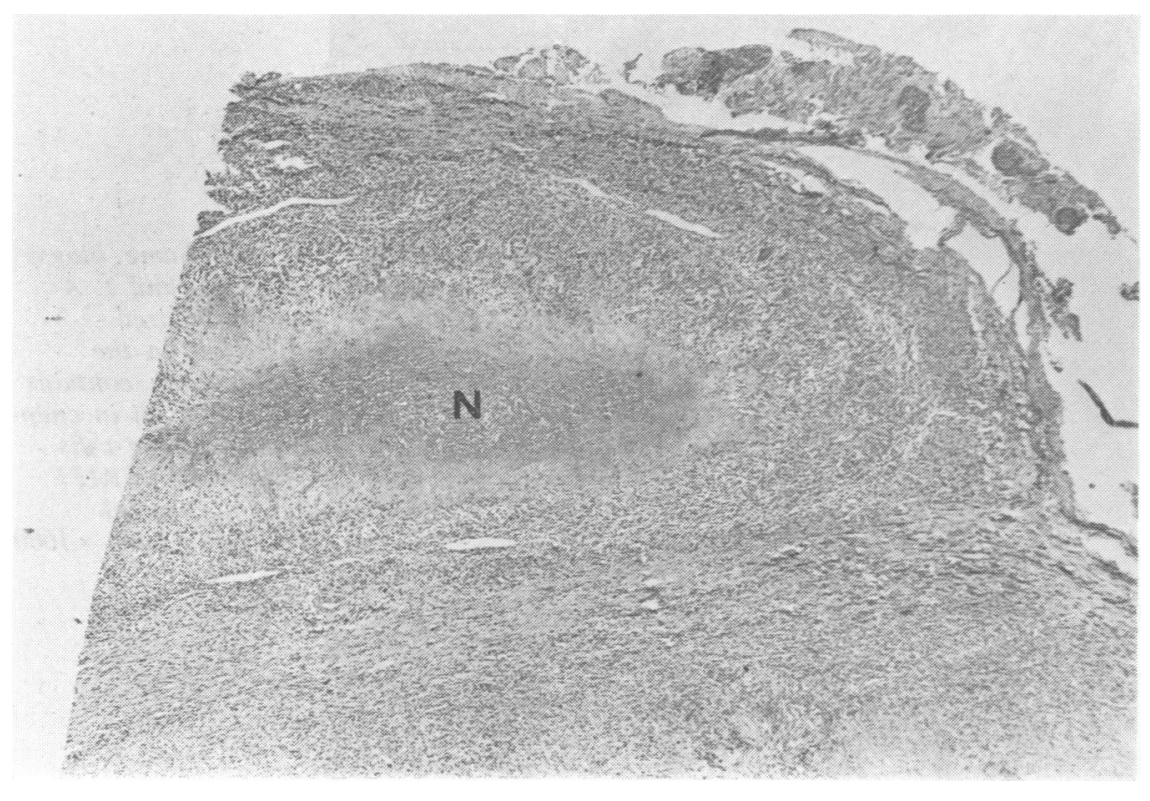

Fig 4 Superficial radial nerve at wrist. $B T$ leprosy: longitudinal section. There is extensive tissue necrosis $(N)$ in the endoneurial zone and the perineurium is heavily infiltrated by histiocytes, lymphocytes and a few giant cells. Bacilli were not found. TRIFF stain. Original magnification $\times 25$. 


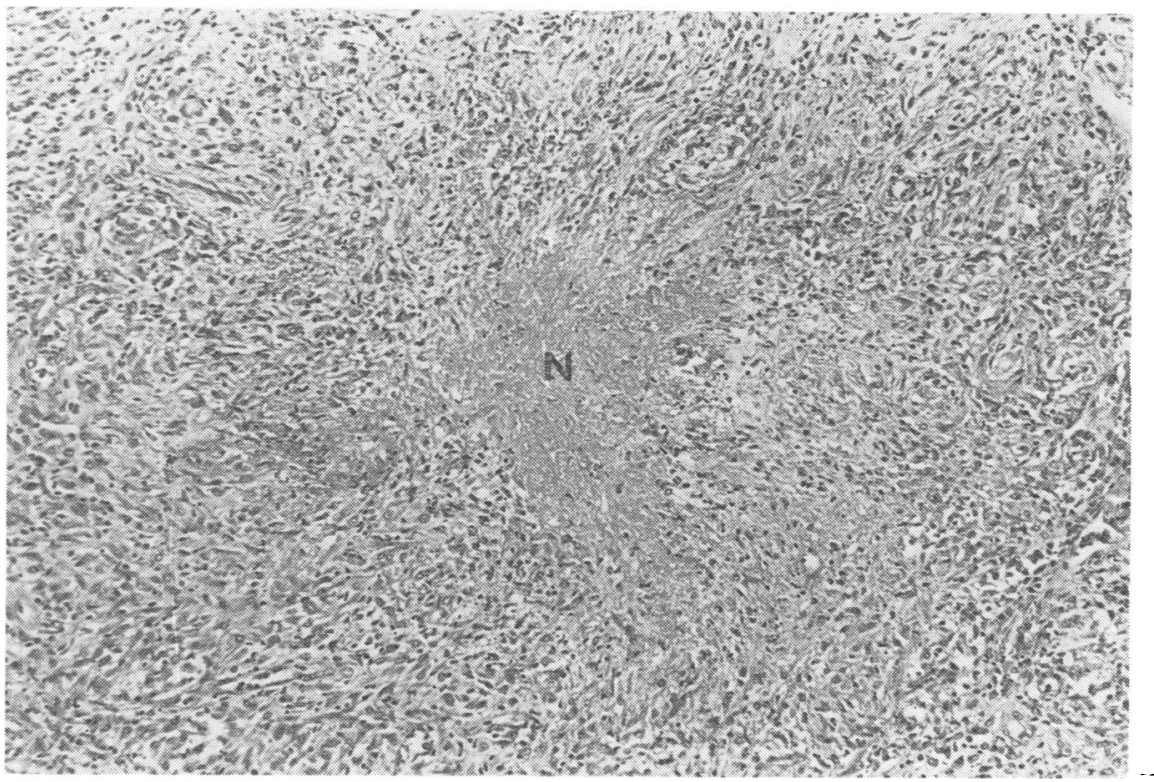

Fig 5 Same biopsy as fig 4. BT leprosy. In the centre of the endoneurial zone there is an area of tissue necrosis ( $N$ ), surrounded by intense histiocyte-lymphocyte infiltrate. TRIFF stain. Original magnification $\times 160$.

patients who had the most severe and widespread neurological damage in this study were in the borderline-lepromatous (BL) group. We believe this to be due to the unfortunate association of two factors-a fairly widespread (though not necessarily complete and symmetrical) seeding of peripheral nerves with bacilli, and a rotential on the part of the immunologically unstable BL patient to produce, within nerves (and elsewhere), a cell-mediated immune response which may in itself be damaging. It may be relevant that levels of IgG in the serum have recently been shown (Samuels, personal communication, 1979) to be highest, not in lepromatous (LL) but in borderline-lepromatous (BL) patients.

As regards symptomatology in lepromatous lepresy, it should be emphasised that by no means all the patients whose biopsies are analysed in this study had symptoms referable to the nerve biopsied, or the peripheral nerves generally. Indeed, as in other parts of the world, the more lepromatous the findings, in general the less marked were the symptoms. By the time these outset biopsies of peripheral nerve were taken, all lepromatous patients in this series had fcsitive skin smears for leprosy bacilli from multiple sites, together with highly positive smears from the nasal mucus. In considering all the prartical problems of diagnosing and treating lepromatous leprosy at an early stage, it is probably significant that those who attended were mainly men who had the determination to walk long distances to the hospital for diagnosis, and it is possible that they represent in Nepal, as in many other countries, only the tip of an "iceberg" of infection of much greater size.

The present data, taken from experience of one observer only, underline the clinical and therapeutic problems attendant upon neural invasion in leprosy. In this tissue, bacilli seem to find ideal conditions for multiplication and vital structures may be damaged if their presence generates immunological reactions. The treatment of the bacillary infection in nerves is still far from satisfactory, and prevention and treatment of adverse reactions under field conditions in countries like Nepal, including the use of drugs such as thalidomide and the steroids, is fraught with difficulties. What appears "early" clinically in leprosy may be disturbingly late on histopathological examination of a nerve biopsy.

We are indebted to Dr SG Browne, Director of the Leprosy Study Centre, for permission to examine clinical records and refer to histopathological reports. AC McDougall is supported by the British Leprosy Relief Association (LEPRA) and a grant from the Oxfordshire Area Health Authority (Teaching). 


\section{References}

1 Browne SG. Some less common neurological findings in leprosy. International Journal of Leprosy 1965; 33:881-91.

2 Browne SG. Leprosy-clinical aspects of nerve involvement. In: Hornabrook RW, ed. Topics on Tropical Neurology, 1975.

3 Crawford CL. Neurological lesions in leprosy. Leprosy Review 1968; 39:9-13.

4 Karat ABA, Furness MA, Karat S, Rao PSS. Patterns of neurological involvement in relation to chronic and/or recurrent erythema nodosum leprosum. Leprosy Review 1969; 40:49-53.

5 Sabin TD, Ebner JD. Patterns of sensory loss in lepromatous leprosy. International Journal of Leprosy 1969; 37:239-48.

6 Karat S, Rao PSS, Karat ABA. Prevalence of deformities and disabilities among leprosy patients in an endemic area. International Journal of Leprosy 1972; 40:265-270.

7 Furness MA, Ranney DA. Nerve enlargement in relation to classification of leprosy. Leprosy Review 1971; 42:208-18.

8 Iyer CGS. Predilection of Mycobacterium leprae for nerves; neurohistopathologic observations. International Journal of Leprosy 1965; 33:634-45.

9 Job CK, Desikan KV. Pathological changes and their distribution in peripheral nerves in lepromatous leprosy. International Journal of Leprosy 1968; 36:257-70.

10 Dastur DK, Pandya SS, Antia NH. Nerves in the arm in leprosy. 2: Pathology, pathogenesis and clinical correlations. International Journal of Leprosy 1970; 38:30-48.

11 Skinsnes OK, Yamashiro KM. Morphology and pathogenesis of peripheral nerve involvement in leprosy. US-Japan Cooperative Medical Science Program. International Journal of Leprosy 1970; 38:351-2.

12 Job CK. Pathology of peripheral nerve lesions in lepromatous leprosy-a light and electron microscope study. International Journal of Leprosy 1971 ; 39:251-68.

13 Sunderland $S$. The internal anatomy of nerve trunks in relation to the neural lesions of leprosy. Brain 1973; 96:865-88.

14 Antia NH. Significance of nerve involvement in leprosy. Plastic and Reconstructive Surgery 1974; 54:55-63.

15 Nishiura M. Electron microscopic basis of the pathology of leprosy. International Journal of Leprosy 1960; 28:357-400.

16 Dastur DK, Ramamohan Y, Shah JS. Ultrastructure of lepromatous nerves. Neural pathogenesis in leprosy. International Journal of Leprosy 1973; 41:47-80.

17 Job CK. Mycobacterium leprae in nerve lesions in lepromatous leprosy. Archives of Pathology 1970; 89:195-207.

18 Kahn P, Scott T. The pathology of radial nerve biopsy in leprosy; a light and electron microscope study. Journal of Pathology 1974; 114:97-100.

19 Dash MS. A study of the conduction velocity of sensory fibres of the ulnar nerve in leprosy. International Journal of Leprosy 1967; 35:460-9.

20 Verghese M, Ittamani KV, Satyanaryana KR, Mathai R, Bhakthavizim CA. A study of the conduction velocity of the motor fibres of ulnar and median nerves in leprosy. International Journal of Leprosy 1970; 38:271-7.

21 Naafs B, Pearson JMH, Baar AJM. A follow-up of nerve lesions in leprosy during and after reaction using motor nerve conduction velocity. International Journal of Leprosy 1976; 44:188-97.

22 Weddell AGM, Pearson JMH. Leprosy-Histopathologic aspects of nerve involvement. In: Hornabrook RW, ed. Topics on tropical neurology. Philadelphia: F A Davis Company, 1975.

23 Pedley JC. Presence of $M$. leprae in human milk. Leprosy Review 1967; 38:239-42.

24 Pedley JC. Presence of $M$. leprae in the lumina of the female mammary gland. Leprosy Review 1968; 39:4, 201-2.

25 Pedley JC. Composite skin contact smears: a method of demonstrating the non-emergence of $M$. leprae from intact lepromatous skin. Leprosy Review 1970; 41:31-43.

26 Pedley JC. The nasal mucus in leprosy. Leprosy Review 1973; 44:33-5.

27 Pedley JC, Geater JG. Does droplet infection play a role in the transmission of leprosy? Leprosy Review 1976; 47:97-102.

28 Ridley DS, Jopling WH. Classification of leprosy according to immunity. A five-group system. International Journal of Leprosy 1966; 34:255-73.

29 Ridley DS, Waters MFR. Significance of Variations within the Lepromatous Group. Leprosy Review 1969; 40:143-52.

30 Harman DJ. Biopsies in leprosy. Leprosy Review 1975; 46:125-34.

31 Wheeler EA, Hamilton EG, Harman DJ. An improved technique for the histopathological diagnosis of leprosy. Leprosy Review 1965; 36: 37-9.

32 Rees RJW, Valentine RC. The appearance of dead leprosy bacilli by light and electron microscopy. International Journal of Leprosy 1962; 30:1-9.

33 Ridley DS. Histological classification and the immunological spectrum of leprosy. Bulletin of the World Health Organisation 1974; 51:451-65.

34 Waters MFR, Rees RJW, McDougall AC, Weddell AGM. Ten years of dapsone in lepromatous leprosy; clinical, bacteriological and histological assessment and the finding of viable bacilli. Leprosy Review 1974; 45:288-98.

35 Godal T. The immune system as benefactor and troublemaker; the case of leprosy. Lab-Lore 1974; 6:305-8.

36 WHO. Leprosy Weekly Epidemiological Record. No 3, 1979; 17-23. 